\title{
AS MÍDIAS DIGITAIS NO CONTEXTO DA SOCIEDADE CONTEMPORÂNEA: INFLUÊNCIAS NA EDUCAÇÃO ESCOLAR
}

\author{
DIGITAL MEDIA IN THE CONTEXT OF CONTEMPORARY SOCIETY: INFLUENCES ON SCHOOL \\ EDUCATION
}

\section{LOS MEDIOS DIGITALES EN EL CONTEXTO DE LA SOCIEDAD CONTEMPORÁNEA: INFLUENCIAS EN LA EDUCACIÓN ESCOLAR}

\author{
Reginaldo Peixoto ${ }^{1}$ \\ Eloisa Elena de Moura Santos Oliveira²
}

\begin{abstract}
RESUMO
O objetivo deste texto é apresentar uma discussão sobre os caminhos percorridos pelas tecnologias da informação e comunicação - TIC e sua influência na sociedade e na educação, ainda que de forma bastante breve. Assim, por meio da pesquisa bibliográfica, tomaremos as mídias digitais como ferramentas influenciadoras de mudanças nos modos de viver ao longo dos tempos e, principalmente, na atualidade, uma vez que elas estão presentes em muitos espaços de atividades humanas, inclusive, no dia a dia da escola e no trabalho que desenvolvem os docentes. A educação, por ser mutável, pode contribuir para uma maior inclusão dos sujeitos escolares no mundo das tecnologias, propiciando ambientes de aprendizagens colaborativas entre alunos e professores. Por isso, defendemos que os processos escolares, além de propiciar vivências dos educandos com as ferramentas tecnológicas, vislumbrem também a formação continuada dos seus profissionais, pois a escola, enquanto espaço de representação da sociedade, precisa, na medida do possível, se aproximar de suas práticas.
\end{abstract}

PALAVRAS-CHAVE: Educação. Inclusão digital na educação. Aprendizagem. Mídias digitais.

\section{ABSTRACT}

The purpose of this text is to present some discussion on the paths taken by information and communication technologies - ICT and its influence on society and education, albeit in a very brief way. Thus, through bibliographic research, we will take digital media as tools that influence changes in ways of living over time and,

Submetido em: 20/08/2020 - Aceito em: 07/12/2020 - Publicado em: 25/01/2021

\footnotetext{
1 Formado em Letras, Pedagogia e Arte/Educação, Mestre em Educação e Doutor em Educação, Arte e História da Cultura. Professor no curso de Pedagogia e Mestrado em Educação na UEMS, Unidade de Paranaíba - MS. Coordenador do Programa Residência Pedagógica do curso de Pedagogia EaD UEMS, no polo de Aparecida do Taboado - MS. E-mail: regi.peixoto77@gmail.com

2 Formada em Pedagogia, Mestranda em Educação na UEMS, Unidade de Paranaíba - MS. E-mail: eloisaelenams@ hotmail.com
} 
especially, nowadays, since they are present in many spaces of human activities, including the day school day and in the work that the teachers develop. Education, as it is changeable, can contribute to a greater inclusion of school subjects in the world of technologies, providing collaborative learning environments between students and teachers. Therefore, we defend that the school processes, in addition to providing students' experiences with technological tools, also envision the continuing education of their professionals, since the school, as a space for representing society, needs, as far as possible, to approach their practices.

KEYWORDS: Education. Digital inclusion in education. Learning. Digital media.

\section{RESUMEN}

El propósito de este texto es presentar una discusión sobre los caminos de las tecnologías de la información y la comunicación: las TIC y su influencia en la sociedad y la educación, aunque de manera muy breve. Así, a través de la investigación bibliográfica, tomaremos los medios digitales como herramientas que inciden en cambios en las formas de vida a lo largo del tiempo y, especialmente, en la actualidad, ya que están presentes en muchos espacios de la actividad humana, entre ellos, en en la jornada escolar y en el trabajo que desarrollan los docentes. La educación, al ser cambiante, puede contribuir a una mayor inclusión de las asignaturas escolares en el mundo de las tecnologías, proporcionando entornos de aprendizaje colaborativo entre alumnos y profesores. Por ello, defendemos que los procesos escolares, además de dotar de herramientas tecnológicas a las experiencias de los alumnos, también vislumbran la formación continua de sus profesionales, ya que la escuela, como espacio de representación de la sociedad, necesita, en la medida de lo posible, acercarse sus prácticas.

PALABRAS CLAVE: Educación; Inclusión digital en educación; Aprendizaje; Medios digitales.

\section{INTRODUÇÃO}

As reflexões em torno da terminologia mídias digitais vêm sendo aprofundadas nos últimos anos e constatando a sua influência na formação do sujeito contemporâneo e da necessidade em explorar o assunto diante do rápido desenvolvimento das novas tecnologias da comunicação e informação.

Quando falamos propriamente sobre mídias digitais, é necessário referir-nos à sua complexidade ao estabelecê-la como produto que se desenvolveu a partir dos anos de 1940, no contexto da ordem industrial. Nesta época, a concentração econômica e administrativa aliada ao desenvolvimento tecnológico estabelecia semelhança estrutural ao cinema, rádio e revistas.

Já, sobre o conceito de mídias digitais o sociólogo Richard Miskolci compreende que:

[...] Mídias digitais são uma forma de se referir aos meios de comunicação contemporâneos baseados no uso de equipamentos eletrônicos conectados em rede, portanto referem-se - ao mesmo tempo - à conexão e ao seu suporte material. Há formas muito diversas de se conectar em rede e elas se entrecruzam diversamente segundo a junção entre tipo de acesso e equipamento usado [...] (MISKOLCI, 2011, p.12). 
Nesse argumento, o conceito de mídias digitais é entendido como um conjunto de objetos tecnológicos, onde os seus usos "mediam as relações sociais por meio da conectividade". (PRADO, 2015, p. 28)

É notório observar que tradicionalmente a sociedade impôs às instituições escolares a responsabilidade na formação da personalidade do indivíduo tendo em vista a transmissão cultural e do conhecimento acumulado historicamente.

Porém, mesmo tentando se desenvolver com o objetivo de formar cidadãos ativos, criativos, críticos no que diz respeito às tecnologias da comunicação e informação, a escola ainda não encontrou meios para que isso se objetivasse.

Alguns estudos sobre as tecnologias e mídias digitais mostram que elas estão, de certa forma, inseridas na maioria das escolas públicas do país, porém, simplesmente como ferramentas de aprendizagem, mostrando insuficiência em seus usos. Na verdade, o que precisa ser compreendido, é como as mídias digitais transcendem os espaços de ensino e aprendizagem e qual o desafio que os seus despontar colocam à educação na contemporaneidade. Por isso, é necessário referi-las como importantes esferas de análise da educação como relação social, no sentido de entender que a maneira de adquirir conhecimento na sociedade em rede não é mais a mesma de quando estudávamos - os equipamentos mudaram, assim como mudaram as suas finalidades.

Mediante esse quadro, este trabalho não vem questionar se a escola pública deveria, ou não, incorporar as mídias digitais em suas práticas pedagógicas, porém, sobre um olhar sociológico, é relevante acrescentar que a abordagem aqui discorrida, enfoca nas influências que as mídias digitais têm na sociabilidade escolar. Desta forma, a partir do objeto de estudo, pretende-se suscitar discussões sobre como e o que ensinar na atualidade, já que o conhecimento está acessível e a escola não é mais o único lugar de adquiri-lo. Também pretende-se discutir questões sobre qual o papel da escola no mundo da conectividade. Contudo, o que almeja é perceber e compreender a influência das mídias digitais no contexto escolar.

\section{ALGUNS ELEMENTOS HISTÓRICOS SOBRE AS MÍDIAS DIGITAIS}

$\mathrm{Na}$ tentativa de reconhecer o contexto histórico de como as mídias digitais estão inseridas na sociabilidade das pessoas, e principalmente, no espaço escolar, trazemos os dizeres de Miskolci que discute que 
[...] reconhecer as continuidades entre o passado e o presente também auxilia a evidenciar as verdadeiras rupturas, as quais, mesmo sendo novidades podem ser mais bem analisadas em contraste com o que se dava antes do acesso às mídias digitais (MISKOLCI, 2011, p.18).

De acordo com o excerto, precisamos novas formas de vivenciar a comunicação, os afazeres diários, as ferramentas de trabalho. $\mathrm{O}$ momento atual é de ruptura com práticas de períodos anteriores, pois a manualidade de espaço à conectividade, ao fazer digital.

Para Adrian Athique (2013), as tecnologias digitais se originaram das máquinas de calcular criadas no século XIX por Charles Babage na década de 1830 e também pelo armazenamento de dados em cartões perfurados, peça chave do desenvolvimento da computação no século XX.

No ano de 1936, Alan Turing criou a máquina universal que era capaz de processar cálculos matemáticos e algoritmos. Esta invenção fez de Alan Turing "uma das figuras mais influentes da computação e da matemática, junto ao exército Britânico durante a Segunda Guerra Mundial na decifração de códigos secretos alemãs." (PRADO, 2015, p. 25).

De acordo com Fonseca Filho (2007, p. 76),

Um sistema formal automático é um dispositivo físico que manipula automaticamente os símbolos de um sistema formal de acordo com as suas regras. A máquina teórica de Turing estabelece tanto um exemplo da sua teoria da computação quanto uma prova de que certos tipos de máquinas computacionais poderiam ser construídas.

A história da computação, de acordo com o autor do excerto já, desde tenra idade, dava indícios de que a máquina poderia processar informações de forma automática e, logo, substituiria os registros de dados e cálculos realizados de forma manual, pelos sujeitos envolvidos naquele processo.

Segundo a socióloga Juliana do Prado (2015, p. 26), "a partir do final dos anos de 1960, o processamento de informações através da computação se espalhou para além das aplicações militares, adentrando às universidades e corporações comerciais." Em concordância e, quando analisa a ampliação das tecnologias digitais para além de setores públicos e privados, Athique (2013) afirma que esse percurso pode ser caracterizado como substituição da Sociedade Industrial pela Sociedade da Informação. 
A partir da disseminação do uso de redes digitais em meados de 1960, Adrian Athique (2013, p. 10) constata que "o que fez a revolução da informação da década de 1970 tecnologicamente diferentes da época anterior do mainframe - computador de grande porte - foi a realização em grande parte da distribuição da computação.” Nesse contexto, podemos dizer que a trajetória ao redor dos avanços tecnológicos se deu devido aos cenários políticos de guerra e pós-guerra, em torno de interesses militares e comercias por países considerados potências econômicas que, naquela época, devido à grande quantidade de consumidores de eletrônicos envolviam quase a totalidade da sociedade.

Na década de 1980 a produção de computadores pessoais possibilitou que seus usos adentrassem na esfera do trabalho. Logo, a posse de computadores se tornou comum entre as classes médias americanas a partir de meados dos anos 1980 (ATHIQUE, 2013), citado por (PRADO, 2015, p. 27).

Sobre o avanço da informática para várias classes, apregoa que:

A integração dos meios de comunicação gera também uma progressiva fusão das atividades intelectuais e industriais do campo da informação. Jornalistas das redações dos grandes jornais e agências de informação, artistas, comunidade estudantil, pesquisadores trabalham diante de uma tela de computador [...] há um aumento da eficiência informacional a cada dia, e se barateiam cada vez mais os custos tecnológicos. Não esquecendo que o computador, diferentemente das outras máquinas (que manipulam, transformam ou transportam matéria e energia) manipula, transforma e transporta um elemento muito mais limpo e menos consumidor de energia e matéria prima. Abre-se, portanto, uma porta para um crescimento da informação praticamente ilimitado (FONSECA FILHO, 2007, p. 138).

De acordo com o autor do excerto, a difusão da informática levou a sociedade a uma nova forma de relacionamento com suas atividades artísticas, laborais e de estudos. Os insumos relacionados à informática foram se barateando, atingindo maiores grupos de pessoas e, com isso, o acesso à informação se tornou algo mais democratizado e com custos muito mais baixos do que outras ferramentas já conhecidas, como por exemplo, transportar uma enciclopédia de um lugar a outro. 
Ao corroborar com Fonseca Filho (2007), Athique (2013) observa que nos anos de 1990 houve um grande barateamento nas produções de computadores. Os softwares foram padronizados e os computadores pessoais tornaram-se comuns na vida das pessoas de classe média. Nesta mesma época, as privatizações das telecomunicações, permitiram a introdução da internet comercial no Brasil. E, com a criação do World Wide Web (WWW) padronizou-se a navegação na internet onde, através de software, "permitia os usuários a visitar facilmente documentos em qualquer número de redes diferentes e navegar através de informações em todo o sistema de redes de computadores interligados (a Internet)" (ATHIQUE, 2013, p. 13).

Nos anos 2000 a internet foi aprimorada, permitindo a interação entre os usuários, possibilitando-os a fazerem comentários sobre o conteúdo que consumia. Neste período, surgiram as mídias digitais.

Contudo, a expansão das novas mídias avançadas em meados dos anos 2000 define um novo paradigma de sociedade, o qual Manuell Castells (1999) denomina de "sociedade de rede", na qual a conectividade assume caráter central. De acordo com Manuel Castells, este novo paradigma tecnológico, vem construindo novos agrupamentos humanos que cada vez mais vem agregando o mundo em grandes redes local-global. Este novo modo de comunicação apresenta cada vez mais elementos genéricos como linguagem, imagens, cultura, política, economia, identidade e etc. Em suma, estas redes de comunicação estão “[...] moldando a vida e, ao mesmo tempo, sendo moldadas por ela." (CASTELLS, 2000, p. 22).

$\mathrm{Na}$ atualidade, as mídias digitais são utilizadas para uma série de atividades humanas: comunicar-se em tempo real, estudar por meio de aplicativos e plataformas digitais, para entretenimento, para comprar e vender produtos dos mais variados gêneros, para conhecer lugares, fazer pesquisas e tantas outras necessidades que diariamente surgem nos meios virtuais. 


\section{O USO DE MÍDIAS DIGITAIS NA EDUCAÇÃO ESCOLAR}

O uso das ferramentas tecnológicas tem avançado em grandes escalas e atingido muitos setores da vida social e, na educação, não poderia ser diferente, pois o impacto desse avanço se efetiva como processo social, adentrando a muitas instituições públicas e privadas, invadindo a vida do homem adentrando em sua casa, na rua onde mora, no supermercado, no seu trabalho, na escola, nas salas de aulas, etc. Deste modo, a influência das mídias digitais, vivenciada pelos atores sociais, direciona suas atividades e suas relações com outras pessoas.

Em nosso novo mundo - influenciado pelos aparatos tecnológicos e mídias digitais, o fluxo de informações é bastante intenso e se mantém em permanente mudança, por isso "o conhecimento é um recurso flexível, fluido, sempre em expansão e em mudança” (HARGREAVES, 2003, p. 33). Um mundo desterritorializado, sem limites de tempo e de espaço para que as pessoas se comuniquem. Um novo tempo de inúmeras possibilidades de aprender, onde o espaço físico da escola, tão protuberante em outros tempos, deixa de ser o local exclusivo para a construção do conhecimento - há outros espaços pertinentes para tal prática humana, inclusive os virtuais.

Dessa forma, ao reconhecermos que vivemos em uma sociedade onde a tecnologia está sempre avançando, reconhecemos também que não podemos retroceder ou desvaler do potencial que as mídias digitais apresentam, inclusive, quando incorporadas à educação. Para Castells (1999, p. 37), "[...] é nessa sociedade que vivemos e ela é a que devemos conhecer se quisermos que nossa ação seja ao mesmo tempo relevante e responsável", ou seja, as nossas vivências podem e devem ser construídas a partir do modelo de sociedade a que estamos vinculados - no nosso caso, uma sociedade da comunicação e informação, mediada pelos recursos tecnológicos digitais.

Essa mudança na sociedade, devido ao advento das tecnologias e mídias digitais, vem mostrando à escola e, portanto, os professores e todos os responsáveis pela educação, a necessidade de entender como o conhecimento é construído na "sociedade em rede". Portanto, 
é também necessário conhecer o processo de utilização, integração e apropriação das tecnologias e mídias digitais às práticas pedagógicas.

Sobre o uso das tecnologias da informação e comunicação e suas relações com a educação apregoa:

As tecnologias de informação e comunicação estão alterando a relação entre ensinar e aprender. Abrem novos horizontes e oferecem aos educadores a possibilidade de utilizar diversas ferramentas que podem melhorar o processo de ensinoaprendizagem, tornando o ato de aprender mais interativo, concreto e cooperativo (NUNES, 2013, p. 24).

Em um mundo mediado pelas mídias digitais, as relações entre professor e estudante, passaram por intensas mudanças, obrigando os educadores a repensarem seus conceitos frente ao fato de não serem mais a única fonte do conhecimento no espaço escolar. É impossível ignorar as experiências vivenciadas por escolares com as mídias digitais, pois à medida em que elas vão sendo inseridas nos mundos onde convivem, vão sendo vivenciadas por eles. Além do mais, quase todo o conhecimento está, na atualidade, disponível em rede, em fácil acesso, por isso, os estudantes também se tornam protagonistas de suas aprendizagens.

As mídias digitais influenciam a educação no sentido de que elas fazem parte da vivencia do estudante e de grande parte da sociedade. Sendo assim, elas possibilitam a aprendizagem colaborativa, permitindo aos estudantes a interação entre si, se apropriando de outras culturas e, consequentemente, melhorando a compreensão de novas e diferentes visões de mundo. Nesse mundo mediado pelas mídias digitais, é necessário que os estudantes trabalhem como colaboradores em projetos dentro ou fora das escolas, que pesquisem, coletem dados, escrevam, publiquem, editem vídeos de forma cooperativa com outros estudantes. Porém, é importante que os professores estejam preparados para trabalharem com tais competências e tenham suas ações sempre planejadas (NUNES, 2013).

Para tanto, a proposição de um trabalho com mídias digitais na escola acontecerá a partir do momento que as políticas públicas de educação possibilitar recursos para aquisição de 
aparelhos tecnológicos e conhecimentos - formação continuada - sobre o tema aos professores, gestores e responsáveis pela escola, pois os profissionais da educação, ainda sentem-se inseguros e despreparados acerca da incorporação das tecnologias às práticas pedagógicas, muitas vezes sabem menos que os próprios alunos.

Sobre a aprendizagem do professor acerca do uso de ferramentas digitais Kenski (2009, p.103) afirma que:

[...] um dos grandes desafios que os professores brasileiros enfrentam está na necessidade de saber lidar pedagogicamente com alunos e situações extremas: dos alunos que já possuem conhecimentos avançados e acesso pleno às últimas inovações tecnológicas aos que se encontram em plena exclusão tecnológica; das instituições de ensino equipadas com mais modernas tecnologias digitais aos espaços educacionais precários e com recursos mínimos para o exercício da função docente. $\mathrm{O}$ desafio maior, no entanto, ainda se encontra na própria formação profissional para enfrentar esses e tantos outros problemas.

De acordo com o autor do excerto há vários problemas que incidem sobre o uso das tecnologias digitais na prática pedagógica, tanto por conta da diversidade de sujeitos educandos que possuem vivências e conhecimentos diversificados, quanto por causa dos recursos tecnológicos serem eficientes e o professor não dominar seu uso, ou por ineficiência e sucateamento. Por isso, nas situações adversas, é preciso contar com processos formativos mais eficientes, de modo a compreender tantos os sujeitos tecnológicos, quanto a função das ferramentas mais modernas.

Dadas as especificidades da educação de crianças e jovens, ressalta-se a necessidade de os profissionais envolvidos no contexto escolar apropriarem-se de teorias da sociedade em rede, do mundo da conectividade, e, por conseguinte, da ideia de que os estudantes de hoje não aprendem como aprendemos no passado. Nesse sentido, percebe-se que a formação continuada é uma necessidade, pois, muitas vezes a formação inicial não fornece os subsídios necessários para que os docentes utilizem, integrem e apropriem-se das mídias digitais nas práticas de sala de aula. Por isso, Candau (2016) observa que para desenvolver uma atividade docente que dialogue com as necessidades atuais, o professor precisa se preparar para enfrentar o cotidiano imprevisível da sala de aula e, um desses meios, seria a formação em serviço, ou formação continuada.

Além do mais, é preciso criar mecanismos que permitam a integração das mídias digitais na educação, onde sua utilização seja segura e crítica na busca de informação, comunicação e 
resolução de problemas em todas as esferas da vida. Portanto, é imprescindível enfatizar a importância da formação integral do estudante, da formação humana, que oportunize o desenvolvimento de habilidades e competências que corroborem para a transformação de uma sociedade justa.

\section{O PAPEL DA ESCOLA NO MUNDO CONECTADO}

Diante das reflexões sobre a influência das mídias digitais no contexto escolar, evidencia-se que "As novas tecnologias da informação não são simplesmente ferramentas a serem aplicadas, mas processos a serem desenvolvidos" (CASTELLS, 1999, p. 69). Nos espaços sociais que as tecnologias da comunicação e informação se fazem presentes, elas são vivenciadas, inclusive, muitas pessoas dependem delas para as vivências do dia a dia.

Nesse contexto, a escola precisa encontrar sua necessária função no mundo da conectividade, levando em consideração a sua influência na formação do sujeito contemporâneo, o qual encontra-se cada vez mais ligado ao desenvolvimento das tecnologias e mídias digitais.

Sobre a necessidade de a escola se adaptar às práticas culturais, Saviani (2008, p. 13) discute que

[...] o trabalho educativo é o ato de produzir, direta e intencionalmente, em cada indivíduo singular, a humanidade que é produzida histórica e coletivamente pelo conjunto dos homens. Assim, o objeto da educação diz respeito, de um lado, à identificação dos elementos culturais que precisam ser assimilados pelos indivíduos da espécie humana para que eles se tornem humanos e, de outro lado e concomitantemente, à descoberta das formas mais adequadas para atingir esse objetivo (SAVIANI, 2008, p. 13).

De acordo com o autor do excerto, a educação e a própria escola precisam dar conta de compreender as novas relações sociais e, a partir delas identificar o que precisa ser apresentado aos alunos enquanto novas aprendizagens e ensina-los pois isso os tornará sujeitos humanos, ou seja, socializados e atentos às mudanças que a todo momento são vislumbradas na sociedade.

Com as mudanças sociais ocorridas pelo avanço acelerado das tecnologias e mídias digitais, a escola se vê frente à necessidade de se adequar em seus métodos de ensino, “[...] pois os alunos que estão na escola hoje são muito diferentes dos alunos que fomos" (TANCREDI, 2009. p. 11). Com isso, "o conhecimento educacional disponível também não é mais o mesmo e afeta sobremaneira a forma como se compreende a aprendizagem, e consequentemente, o ensino" (Tancredi, 2009, p. 11). 
No que diz respeito ao uso das ferramentas digitais, Behrens (2007, p. 77) também observa que

Num mundo globalizado, que derruba barreiras de tempo e espaço, o acesso à tecnologia exige atitude crítica e inovadora, possibilitando o relacionamento com a sociedade como um todo. $\mathrm{O}$ desafio passa por criar e permitir uma nova ação docente na qual professor e alunos participam de um processo conjunto para aprender de forma criativa, dinâmica, encorajadora e que tenha como essência o diálogo e a descoberta (Behrens 2007, p. 77).

Na reflexão da autora, a ação docente que vislumbra o uso de ferramentas tecnológica passa pelo desafio de o professor se envolver e envolver os escolares, pois se trata de uma ação conjunta, onde os atores fazem descobertas coletivas, pois aprendem juntos, e isso, acaba por criar um maior diálogo entre professores e alunos.

Sobre esse entendimento, a escola precisa apoderar-se da mudança que transpassa a sociedade, pois as crianças e adolescentes precisam estar preparados para viver e atuar nela. Desse modo, Tancredi (2009, p. 11) corrobora com Saviani (2008), quando admite que:

[...] os professores precisam compreender a sociedade em que seus alunos vivem se querem bem prepará-los para ela. Ora, isso exige que sejam "cidadãos do mundo", no sentido de que se formem não apenas como profissionais, mas se desenvolvam no âmbito pessoal, social e cultural, ou seja, como pessoa participante dessa mesma sociedade.

Sobre essa compreensão sobre a sociedade que é tratada pela autora do excerto, podemos vale também ressaltar que na sociedade em rede os conhecimentos e habilidades que os professores precisam adquirir e desenvolver para ensinar a essa geração, é sem dúvida, em primeiro lugar, saber usar as tecnologias e mídias digitais em favor da aprendizagem significativa, prazerosa e espontânea. Também é importante saber como as crianças e adolescentes contemporâneos aprendem; valorizar o que eles já sabem e propor atividades que estimulem o protagonismo digital, o trabalho colaborativo e autonomia na busca da sua própria aprendizagem.

Dessa forma, ao percebermos a importância do protagonismo escolar frente à aprendizagem digital, consideramos que o papel da escola no mundo da conectividade é o de garantir a totalidade de pensamento através do domínio teórico, utilizando-se dos meios tecnológicos como processos a serem desenvolvidos para a emancipação, proposta pelo surgimento das mídias digitais, que no século XXI tornou-se um meio de dominação e controle social (OLIVEIRA, 2017). 
E como fazer para tudo isso acontecer? Se a escola, ainda não está conseguindo cumprir o seu papel perante a sociedade atual, entende-se que a formação dos professores, é fundamental, pois é visto que os profissionais da educação da atualidade foram formados para trabalhar em uma sociedade que não existe mais. Além do mais, percebe-se dificuldades dos educadores ao tentarem estabelecer esse novo processo de ensino (TANCREDI, 2009).

Para Antunes (2008), os professores e os alunos precisar caminhar em uma conexão sistemática. Por isso é importante que o docente esteja sempre informado sobre os modos como a sociedade se organiza, assim como das ferramentas que ela faz uso, para que o conteúdo escolar, assim como a aula, não caia na mesmice e os alunos se interessem pela aprendizagem escolar.

Ainda que no Brasil, muitos estudos como de Sá e Werle (2017) apontem para uma péssima estrutura das escolas públicas, vislumbrem a ausência de equipamentos tecnológicos e redes de internet disponíveis para o uso dos alunos e dos professores, vale ressaltar que trata-se de uma necessidade de tê-los, já que as formas de comunicação se espreitaram cada vez mais por meio desse recursos. Prova disso é o ensino remoto emergencial - ERE, instituído em todas as partes do mundo, devido à pandemia de covid19 iniciada na China no final de 2019 e adentrada a todos os outros países a partir do início de 2020.

Na observação que fazem Sá e Werle (2017), quanto pior forem as estruturas das escolas, piores serão as práticas pedagógicas desenvolvidas por seus docentes, o que compromete, em grande escala, o conhecimento e as ações diárias da escola. O professor precisa aprender a lidar com as tecnologias, como bem afirmam Candau (2005) e Antunes (2008), no entanto, não se pondera a que custo se dá essa aprendizagem ou a prática dela.

De acordo com Candau (2005) a educação carece de uma grande transformação, tanto por conta da diversidade de sujeitos que dela fazem parte, quanto pelas transformações que vem ocorrendo nas formas de relacionamentos humanos - isso inclusive, inclusive, a comunicação, o uso das tecnologias e as formas pelas quais nos reinventamos na educação, em função da relação ensino e aprendizagem.

Para Candau (2016, p. 909),

É importante ter presente que já existem nos sistemas educativos experiências "insurgentes" que apontam para outros paradigmas escolares: outras formas de organizar os currículos, os espaços e tempos, o trabalho docente, as relações com as famílias e comunidades, de conceber a gestão de modo participativo, enfatizando as práticas coletivas, a partir de um conceito amplo e plural de sala de aula, etc. Mas 
essas experiências permanecem periféricas, não são adequadamente visibilizadas, nem fortemente apoiadas.

Não nos bastam mais o livro didático, o giz e o quadro. Outras tecnologias foram aos poucos ao longo dos tempos, como também de forma imediata - por conta da pandemia de covid19 inseridas em nossas vidas, no nosso trabalho e em todas as formas de convivência, inclusive aquelas que sempre nos foram pensadas de forma real e hoje facultadas às conexões digitais. Os celulares, os computadores passaram a ser o meio de levar nossos abraços aos familiares, a cantar os parabéns, a tirar as dúvidas dos alunos, explicar os conteúdos e realizar as avaliações. Tivemos que, de fato, reinventar a escola e as práticas pedagógicas, como bem defende Candau (2005) em seus escritos, os quais apontavam essa necessidade.

Muitos problemas de ordem pedagógica foram resolvidos no curso desse ano letivo de 2020, no entanto, essa metodologia não pode ser pensada para todo o sempre na educação, pois se está sendo assertiva ou não, o tempo irá responder, porém, é emergencial, precisa ser repensada e praticada de acordo com as possibilidades e condições dos envolvidos na educação. A experiência poderá demonstrar um novo momento, onde muitos professores e alunos se relacionaram com outras formas de ensinar e aprender.

Não há dúvidas de que a escola não deva ser um parque de professauros (ANTUNES, 2008), os professores precisam aprender a lidar com as tecnologias e colaborar para que os alunos, principalmente aqueles que não as vivenciam diariamente, sejam inseridos nas atuais formas de comunicação, interação e relações com o conhecimento. É mister que a estrutura escolar dê condições mínimas para que isso ocorra.

Sabemos da necessidade de alinhar a educação às tecnologias, no entanto, segundo pesquisa realizada por Sá e Werle (2017, p. 388), quando se trata de escolas públicas

[...] há apenas 0,6\% das escolas de educação básica consideradas adequadas, ou seja, que proporcionavam aos estudantes infraestrutura capaz de atingir os propósitos de uma educação de qualidade. Esse tema, infraestrutura escolar, vem chamando a atenção de estudiosos há alguns anos.

Os esforços que visam mudanças na educação ficam muitas vezes no âmbito da gestão da escola, dos professores e dos alunos. Dessa forma, os responsáveis pela educação do país, precisam refletir com urgência sobre o papel da escola no mundo da conectividade, criar e implementar políticas públicas que assegurem a viabilização desse processo e propor condições para possíveis adequações nos currículos, projetos políticos pedagógicos e, consequentemente, nos planos de aula/ensino. Precisa ser um movimento coletivo em prol da educação. 
A educação precisa acompanhar o desenvolvimento tecnológico e social em prol de melhores experiências que oportunizem de forma igualitária a todos, sem qualquer distinção, pois o que se viu até o momento foram propostas feitas para atender e levantar bandeiras políticas e/ou fortalecer campanhas partidárias de sujeitos incapazes de atuarem como representantes de um povo repleto de desigualdade e injustiça social. A educação precisa ser uma bandeira empenhada por todas as instituições sociais - ao contrário está fadada a permanecer no descaso!

\section{CONSIDERAÇÕES FINAIS}

É notório observarmos que "o surgimento de uma nova visibilidade está definitivamente relacionado a novas maneiras de agir e interagir trazidas com a mídia" (THOMPSON, 2008, p. 17). O que nos era comum hoje se tornou obsoleto e o novo tem se inserido com grande precisão, como no caso das ferramentas diária, as quais utilizamos para nos comunicar.

Nessa circunstância, esse texto trouxe alguns conceitos sobre os elementos históricos e teóricos das mídias digitais, que por sua vez, mostraram que a expansão das novas mídias avançou em meados dos anos 2000, definindo um novo paradigma de sociedade, o qual Manuell Castells (1999) denominou de "sociedade em rede".

O texto avançou nas discussões referentes às mídias digitais na educação e revelou que a mudança ocorrida na sociedade devido o advento das tecnologias da informação e comunicação colocou a escola e, portanto, alguns professores e responsáveis pela educação num contexto de preocupação em entender como o conhecimento é adquirido na sociedade em rede. Nesse ponto de vista, percebeu-se a necessidade de desenvolver formações continuadas para os profissionais da educação, devido, na maioria das vezes, a formação inicial não ter fornecido os subsídios necessários para utilizarem, integrarem e apropriarem das mídias digitais nas suas práticas em sala de aula.

Por fim, o presente texto apresentou questões inerentes ao papel da escola no mundo da conectividade, que no decorrer dos escritos despontou a necessidade de adequação nos currículos escolares, nos projetos políticos pedagógicos, e, consequentemente nos planos de aula, que na atualidade, exige o desenvolvimento de habilidades que permitem ao estudante ao docente serem protagonistas dos processos educativos pois podem aprender de forma colaborativa, com autonomia para buscar informações, se comunicar e resolver problemas em 
todas as esferas da vida, corroborando para a transformação de uma sociedade justa.

A discussão aqui apresentada procurou elucidar, ainda que de forma tímida, o entendimento da influência que as mídias digitais têm no contexto escolar devido a existência de uma nova sociedade decorrente do acelerado avanço tecnológico da informação e comunicação.

Dessa forma, evidenciamos que nesse novo mundo as mídias digitais influenciam, não só o contexto escolar, mas toda a sociedade, já que o mundo está totalmente envolvido com elas, pelo fato de elas possibilitarem a interação e a comunicação de forma rápida e mais acessível. Porém, ainda há muito que ser feito e revisto para que as escolas, de fato, cumpram seu papel de incluir a todos no mundo digital, sem distinção.

Sem dúvidas, será preciso a criação e do desenvolvimento de políticas públicas para o desenvolvimento de formações continuadas a todos os profissionais de educação; da reelaboração dos projetos políticos pedagógicos, maior tomada de consciência da necessidade de um novo currículo que assegure o desenvolvimento de habilidades específicas para os estudantes e os docentes do século XXI. É possível, mas em se tratando de educação, exige garra e perseverança por parte de toda a sociedade.

\section{REFERÊNCIAS}

ANTUNES, Celso. Professores e Professauros: Reflexões sobre a aula e práticas pedagógicas diversas. $2^{\text {a }}$ Ed. - Petrópolis RJ: Ed. Vozes, 2008.

ATHIQUE, Adrian. Digital Media and Society: an Introduction. Cambridge, Polity Press, 2013.

BEHRENS, Marilda Aparecida. Projetos de aprendizagem colaborativa num paradigma emergente. In: José Manuel Moran; Marcos T. Mazetto e Marilda Aparecida Behrens (Orgs.). Novas tecnologias e mediação pedagógica. Campinas: Papirus, 2000. p. 67-132.

CANDAU. Vera Maria Ferrão. Cotidiano escolar e práticas interculturais. Cadernos de Pesquisa v. 46 n. 161 p. 802-820 jul./set. 2016. Disponível em: http://www.scielo.br/pdf/cp/v46n161/1980-5314-cp-46-161-00802.pdf. Acesso em: 10 mar 2020.

CANDAU. Vera Maria Ferrão. Direitos humanos, violência e cotidiano escolar: In: Vera Maria Candau (Org.). Reinventar a escola. Petrópolis RJ: Vozes, 2005. p. 137-166

CASTELLS, Manuel. A Sociedade em Rede. São Paulo, Ed. Paz e Terra, 1999. 
CGI.BR - Comitê Gestor da Internet no Brasil. Pesquisa sobre o uso das tecnologias da informação e comunicação nas escolas brasileira [livro eletrônico] TIC educação 2014. Coordenação executiva e editorial, Alexandre F. Barbosa. São Paulo: Comitê Gestor da Internet no Brasil, 2015. 6,5Mb; PDF. Disponível em:

https://www.cgi.br/media/docs/publicacoes/2/TIC_Educacao_2014_livro_eletronico.pdf. Acesso em 20 nov 20129.

FONSECA FILHO, Cléuzio. História da computação: O Caminho do Pensamento e da Tecnologia. Porto Alegre: EDIPUCRS, 2007.

HARGREAVES, Andy. O Ensino na Sociedade do Conhecimento: a educação na era da insegurança. Colecção Currículo, Políticas e Práticas. Ed, Porto Editora, 2003.

HARGREAVES, Andy. Educação e Tecnologias: o novo ritmo da informação. Campinas, SP: Papirus, 2008.

KENSKI, Vani Moreira. Educação e tecnologias: o novo ritmo da informação. 5.ed. Campinas, SP: Papirus, 2009.

MISKOLCI, Richard. Novas conexões: notas teórico-metodológicas para pesquisas sobre o uso de mídias digitais. Cronos: R. Pós-Grad. CI. Soc. UFRN, Natal, v.12, n.12, p.09-22, jul./dez. 2011.

MISKOLCI, Richard. Sociologia Digital: notas sobre pesquisa na era da conectividade. Contemporânea - Revista de Sociologia da UFSCar, v.6, n.2, jul.-dez. 2016, pp.275-297. NUNES, Rosemeri Coelho. Mídias aplicadas na educação e AVEA. 2. ed. rev.

Florianópolis: IFSC, 2013.

OLIVEIRA, Eloiza S. G. Adolescência, internet e tempo: desafios para a Educação. Educar em Revista, Curitiba, Brasil, n. 64, p. 283-298, abr./jun. 2017. Disponível em: http://www.scielo.br/pdf/er/n64/0104-4060-er-64-00283.pdf. Acesso em 11 mar 2020.

PRADO, Juliana do. Dos consultórios sentimentais à rede: apoio emocional pelas mídias digitais. São Carlos: UFSCar, 2015.

SÁ, Jauri Dos Santos; WERLE, Flávia Obino Corrêa. Infraestrutura escolar e espaço físico em educação: o estado da arte. Cadernos de Pesquisa v.47 n.164 p.386-413 abr./jun. 2017. Disponível em: https://www.scielo.br/pdf/cp/v47n164/1980-5314-cp-47-164-00386.pdf. Acesso em 20 agosto 2020.

SAVIANI, Dermeval. Pedagogia histórico-crítica: primeiras aproximações. Campinas: Autores Associados, 2008. 
TANCREDI, Regina Maria Simões Pulcinelli. Aprendizagem da docência e profissionalização: elementos de uma reflexão. edUFSCar, São Carlos-SP, 2009.

THOMPSON, John B. A Nova Visibilidade. Matrizes, n. 2, abril de 2008. p. 15-38 Disponível em: https://www.revistas.usp.br/matrizes/article/download/38190/40930/. Acesso em 15 dez 2019. que permite uso, distribuição e reprodução para fins não comerciais, com a citação dos autores e da fonte original e sob a mesma licença. 